\title{
Is radiotherapy an effective treatment option for recurrent metastatic malignant melanoma? A case report of short-course, large-fraction radiation and a literature review
}

\author{
Abhirami Hallock MD, Olga Vujovic MD, Edward Yu MD
}

A Hallock, O Vujovic, E Yu. Is radiotherapy an effective treatment option for recurrent metastatic malignant melanoma? A case report of short-course, large-fraction radiation and a literature review. Can J Plast Surg 2011;19(4):153-155.

BACKGROUND: Malignant melanoma is regarded to be radiation resistant. A case of recurrent malignant melanoma with in-transit metastasis treated with short-course, high-fraction palliative radiation is presented to illustrate the effectiveness of radiotherapy.

METHOD: An 80-year-old woman initially treated surgically for a primary malignant melanoma of the left lower leg presented with multiple in-transit metastases. Palliative radiation was offered to treat two fungating in-transit masses that were resistant to treatments of isolated limb infusion and intralesional interleukin-2.

RESULTS: Treatment consisted of short-course, high-fraction radiation with $800 \mathrm{cGy}$ fractions given over three weeks on days 0,7 and 21, for a total dose of 2400 cGy. She experienced a complete response that was maintained for six months.

CONCLUSIONS: Radiation is an effective treatment option for palliation of recurrent malignant melanoma. Complete response is possible even with short-course, high-fraction radiation.

Key Words: In-transit metastases; Recurrent malignant melanoma; Shortcourse radiation

$\mathrm{R}$ ecurrent malignant melanoma presents a treatment challenge, with few long-term survivors with advanced stage disease. Patients with stage IV metastatic disease have a dismal outcome, with a reported five-year survival rate of $5 \%$. However, patients with stage IIIC disease (2009 AJCC Melanoma Staging and Classification system) who have more than four nodal metastases or in-transit metastases, have a significant expected five-year survival of $40 \%$ (1). It is, therefore, important to achieve effective palliation for this group of patients.

Traditionally, malignant melanoma has been considered to be a relatively radioresistant tumour $(2,3)$. This belief has led to patients with recurrent or advanced-stage cutaneous malignant melanoma either not being referred for radiotherapy or being referred as a last resort.

We report a case involving a patient with an advanced locoregional recurrence of a cutaneous malignant melanoma who was referred for palliative radiation as a last resort after failed attempts with numerous other treatment options, including repeat surgical excisions, isolated limb infusion and intralesional injections with interleukin-2.

The present case illustrates the effectiveness of radiation as a treatment option for palliation of advanced-stage malignant melanoma.

\section{CASE PRESENTATION}

An 80-year-old woman presented with a superficial spreading melanoma of the left posterior calf, three years before her referral for a radiation oncology consultation. She was initially treated with excision and skin grafting, with pathology confirming a $0.5 \mathrm{~mm}$ superficial
La radiothérapie est-elle un traitement efficace contre un mélanome métastasique malin récurrent? Rapport de cas de fortes fractions d'irradiation sur une courte période et analyse bibliographique

HISTORIQUE : Le mélanome malin est perçu comme résistant aux radiations. Un cas de mélanome malin récurrent comportant des récidives nodulaires sous-cutanées intermédiaires traité par fortes fractions d'irradiation palliative est présenté pour démontrer l'efficacité de la radiothérapie.

MÉTHODOLOGIE : Une femme de 80 ans ayant été traitée par voie chirurgicale pour soigner un mélanome malin primaire de la jambe gauche inférieure a présenté de multiples récidives nodulaires sous-cutanées intermédiaires. Elle a subi une radiation palliative pour traiter deux masses fongiques résistantes aux traitements d'infusion du membre isolé et d'interleukine-2 intralésionnelle.

RÉSULTATS : Le traitement consistait en de fortes fractions d'irradiation sur une courte période, des fractions de 800 cGy étant irradiées sur une période de trois semaines, les jours 0,7 et 21, pour une dose totale de 2400 cGy. La femme a répondu complètement au traitement et cette réponse s'est maintenue pendant six mois.

CONCLUSIONS : La radiation est une possibilité de traitement efficace pour pallier une récurrence de mélanome malin. Il est possible d'obtenir une réponse complète même au moyen de fortes fractions d'irradiation sur une courte période.

spreading malignant melanoma (T1NOMO), which was completely excised. She was otherwise well and clinical examination revealed no evidence of metastatic disease.

She remained well for two-and-a-half years, at which time she developed numerous in-transit metastases confined to the left lower extremity. Over the following six months, she underwent 12 additional excisions for the in-transit disease. Because she continued to have intractable in-transit disease she was referred for isolated limb infusion therapy. This controlled all of the lesions except for two, and was associated with severe complications including skin breakdown and necrosis. The two resistant lesions continued to grow in size, and repeat biopsies confirmed metastatic malignant melanoma. Further attempts at treating these two lesions included intralesional interleukin-2 therapy, which failed, and an additional attempt at resection, which was incomplete because the tumour was wrapping around the tibial nerve and artery. At this point, she was referred for consideration of palliative radiotherapy.

When she was seen in consultation, she was symptomatic, with pain and swelling of the left lower leg that prevented her from wearing a shoe and walking, which was an activity she had previously enjoyed. She was also anemic from ongoing bleeding of the two fungating in-transit metastases.

Physical examination of the left leg revealed two large, black, fungating skin lesions measuring $4 \mathrm{~cm}$ each, located over the medial malleolus and the lower medial calf (Figure 1). She exhibited no inguinal adenopathy or other clinical evidence of metastatic disease. 


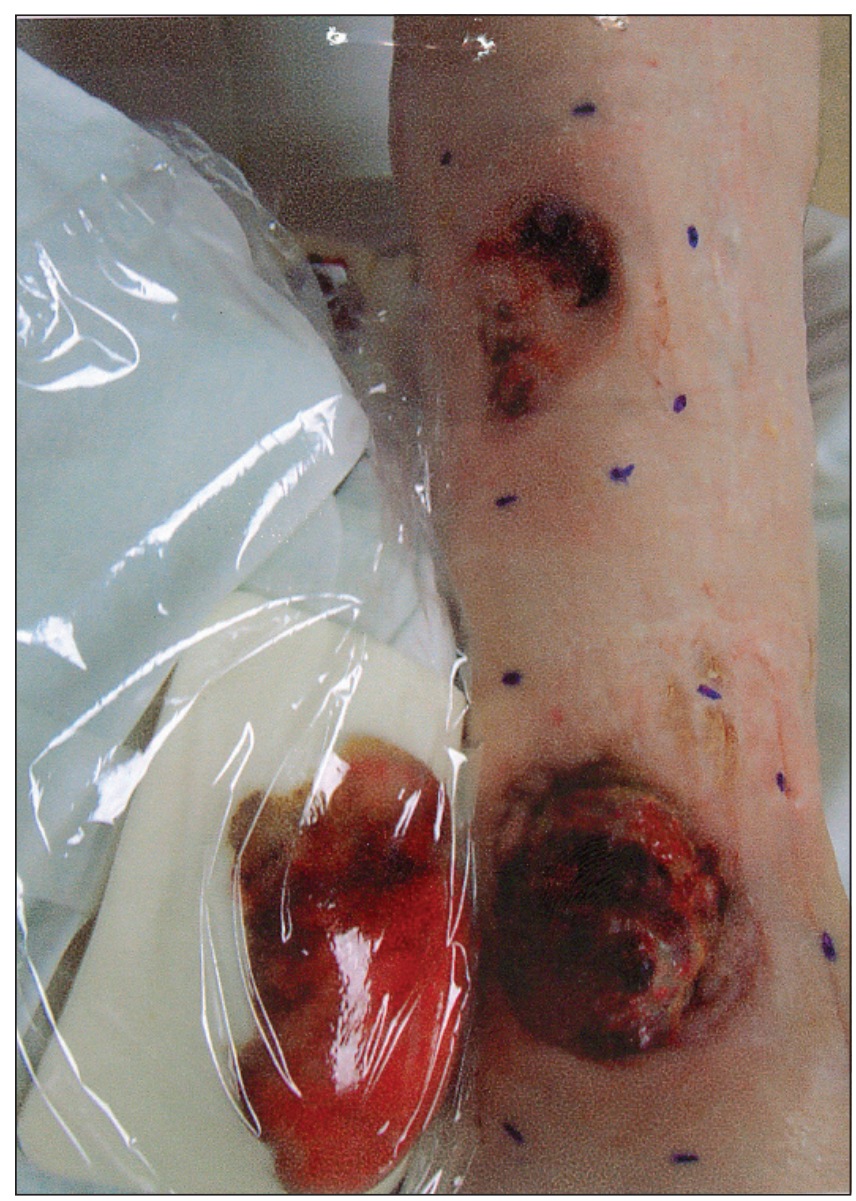

Figure 1) Left lower leg of an 80-year-old woman showing two large, fungating, in-transit metasases

She was offered palliative radiotherapy for the two resistant lesions using a short-course, large-fraction radiation schedule because the patient lived $4 \mathrm{~h}$ away and was not able to undergo daily radiation treatments.

The radiation treatment consisted of a $800 \mathrm{cGy}$ fraction size delivered in three fractions over three weeks on days 0,7 and 21, for a total dose of 2400 cGy. Each lesion was treated with a separate electron radiation field, which treated the lesions while sparing underlying normal structures. She tolerated the radiation well without side effects, and the lesions showed a progressive response with a decrease in size and cessation of bleeding with each fraction of radiation.

At first follow-up at three months, she demonstrated an excellent response, with complete resolution of the lesions and complete healing of the overlying skin (Figure 2). She also had resolution of her leg pain and edema, and was able to wear shoes and walk again. At six months, a small $(<1 \mathrm{~cm})$ recurrent nodule was present at the edge of one of her radiation fields, which was otherwise asymptomatic.

At one year, following her radiotherapy, she developed numerous, rapidly progressing, in-transit metastases of the left lower leg and was offered an above-knee amputation.

\section{DISCUSSION}

Surgery is the mainstay for treatment of primary malignant melanoma and recurrent disease, especially locoregional recurrences. However, when surgery is no longer feasible, patients should be referred for other treatment options.

As previously stated, with respect to radiotherapy, the prevailing belief is that malignant melanoma is radioresistant. However, there have also been reports to the contrary, showing radiosensitivity of malignant melanoma $(4,5)$. There has also been controversy over the

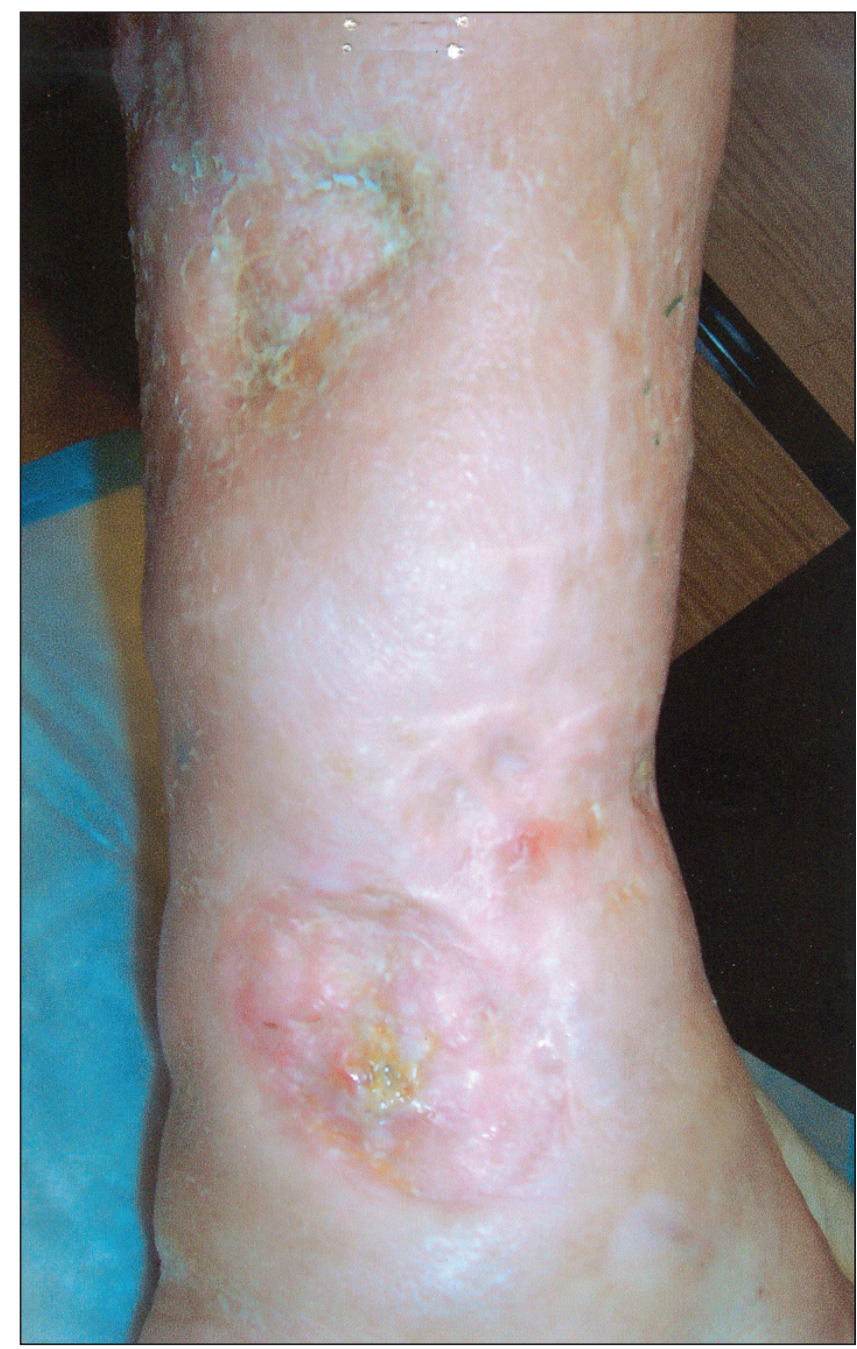

Figure 2) The same leg showing complete resolution of the two tumours, three months following short-course, high-fraction size radiation

most effective dose fractionation in treating malignant melanoma. The most commonly used dose fraction size in the adjuvant setting is 200 cGy per fraction, given daily over several weeks. However, for malignant melanoma, there has been evidence supporting significantly better response rates with fraction sizes $\geq 600$ cGy (6-8). However, a recent, prospective, randomized trial comparing high-dose per fraction radiation ( $800 \mathrm{cGy}$ ) with standard fractionation ( $250 \mathrm{cGy}$ ) showed no difference in response rates (9). Regardless of the dose per fraction schedule, these studies have shown significant response rates, with overall response rates (ORR) of $70 \%$, with complete responses of $25 \%$ $(9,10)$. In comparison, the ORR with dacarbazine, the standard chemotherapy drug for metastatic melanomas, is $10 \%$. Isolated limb infusion used for in-transit metastasis has a higher ORR of $85 \%$, but is associated with significant side effects including skin necrosis and a risk of requiring limb amputation (11). In contrast, radiation of skin metastasis is well tolerated with minimal side effects, as shown in the case example, and can be administered in a convenient short-course schedule.

\section{CONCLUSIONS}

Recurrent malignant melanoma remains a treatment challenge, with a propensity for progressive recurrence despite all available treatments. These tumours should no longer be considered radioresistant. Palliative radiation should be considered early in the management of recurrent disease and should not be a treatment of last resort, which has been the tradition in the past. 


\section{REFERENCES}

1. Balch CM, Gershenwald JE, Soong S. Final version of 2009 AJCC melanoma staging and classification. J Clin Oncol 2009;27:6199-206.

2. Barranco, SC, Romsdahl M, Humphrey RM. The radiation response of human malignant melanoma cells grown in vitro. Cancer Res 1972;31:830-3.

3. Doss LL, Memula N. The radio respnsiveness of melanoma. Int J Radiat Oncol Biol Phys 1982;8:1131-4.

4. Trott KR, von Lievein H, Kummermehr J. The radiosensitivity of malignant melanomas, Part I: Experimental sudies.

Int J Radiat Oncol Biol Phys 1981:7:9-13.

5. Trott KR, von Lievein $\mathrm{H}$, Kummermehr J. The radiosensitivity of malignant melanomas, Part II: Clinical studies.

Int J Radiat Oncol Biol Phys 1981;7:15-20.

6. Habermalz HJ, Fisher JJ. Radiation therapy of malignant melanoma. Cancer 1976;38:2258-62.
7. Adam JE, Habeshaw T, Kirk J. Response rate of malignant melanoma to large fraction irradiation. Br J Radiol 1982;55:605-7.

8. Overgaard J. Radiation treatment of malignant melanoma. Int J Radiat Oncol Biol Phys 1980;6:41-4.

9. Sause WT, Cooper JS, Rush S. Fraction size in external beam radiation therapy in the treatment of melanoma. Int J Radiat Oncol Biol Phys 1991;3:429-32.

10. Seegenschmiedt MH, Keilholz L, Altendorf-Hofmann A. Palliative radiotherapy for recurrent and metastatic malignant melanoma: Prognostic factors for tumor response and long-term outcome: A 20-year experience. Int J Radiat Oncol Biol Phys 1999;44:607-18.

11. Lindnér P, Doubrovsky A, Kam PC, Thompson JF. Prognostic factors after isolated limb infusion with cytotoxic agents for melanoma. Ann Surg Oncol 2002;9:127-36. 